\title{
Leprous Neuropathy: Observational Study Highlighting the Role of Electrophysiology in Early Diagnosis
}

\author{
Beena V. Vijayan ${ }^{1}$ Maria R. Dominic ${ }^{1}$ Vijayan C.P. Nair ${ }^{2}$ \\ ${ }^{1}$ Department of Neurology, Government Medical College Hospital, \\ Affiliated to Kerala University of Health Sciences, Kottayam, \\ Kerala, India \\ ${ }^{2}$ Kerala University of Health Sciences, Thrissur, Kerala, India

\begin{abstract}
Address for correspondence Beena V. Vijayan, MD, DM, DNB, Department of Neurology, Government Medical College Hospital, Affiliated to Kerala University of Health Sciences, Narayaneeyam, Gandhinagar, Thrissur, Kottayam 686008, Kerala, India (e-mail: beenavdr@gmail.com).
\end{abstract}

\section{Abstract \\ Keywords \\ - leprous neuropathy \\ - electrophysiology \\ - nerve conduction study \\ - subclinical \\ - electroclinical dissociation \\ - mosaic pattern \\ - mononeuritis multiplex}

Background Worldwide leprosy is a common cause of peripheral neuropathy. Electrophysiology is underutilized in its diagnosis.

Objective This study aims to evaluate the usefulness of electrophysiological study in the diagnosis of leprous neuropathy.

Materials and Methods Clinical and electrophysiological abnormalities of 36 histopathology proven leprosy patients from January 2015 to January 2017 were studied.

Statistical Analysis Proportions were compared by Chi-square test.

Results Total patients were 36 . Thirty-four patients had abnormal electrophysiology and 34 had neurological deficits like weakness, sensory changes, and thickening. By clinical examination, multiple nerve involvement (motor weakness, sensory changes, and nerve thickening) occurred in 29 , single nerve in 5 , and no nerve involvement in 2 . With electrophysiology, multiple nerve involvement (mononeuritis multiplex) was present in 32 , single nerve in 2 , and normal conduction parameters in 2 . From the 36 patients, a total of 1,008 nerves were subjected to clinical examination and 132 were picked up clinically as affected, (13.1\%). Electrophysiological study was done in 504 nerves, and 215 were found to be involved, (43\%). Nerve abnormality detected by electrophysiology is significantly higher than clinical detection. (Chi-square $=164.4054 ; p=0.0000$ ). Clinically, the most commonly affected nerve was unar (27) and the least affected was median (2) nerve. Electrophysiology detected $69 \%$ of nerves with demyelination and $35 \%$ of nerves with axonal features (mosaic pattern).

Discussion There was subclinical neuropathy with electroclinical dissociation, as evidenced by more abnormality in electrophysiology than clinical examination. The nerve involvement was mononeuritis or mononeuritis multiplex pattern, both clinically and electrophysiologically. Electrophysiology showed both axonal and demyelinating nerve involvement (mosaic pattern). All the three features are present in leprous neuropathy. In corollary, if a patient has these electrophysiological features, he should be thoroughly investigated for leprosy.

Conclusion Triple findings, such as subclinical neuropathy with electroclinical dissociation, mononeuritis multiplex, and mosaic pattern of demyelination and axonopathy, suggest leprous neuropathy published online June 16, 2021
DOI https://doi.org/ $10.1055 / \mathrm{s}-0041-1727575$ ISSN 0976-3147 (c) 2021. Association for Helping Neurosurgical Sick People. This is an open access article published by Thieme under the terms of the Creative Commons Attribution-NonDerivative-NonCommercial-License, permitting copying and reproduction so long as the original work is given appropriate credit. Contents may not be used for commercial purposes, or adapted, remixed, transformed or built upon. (https://creativecommons.org/licenses/by-nc-nd/4.0/).

Thieme Medical and Scientific Publishers Pvt. Ltd. A-12, 2nd Floor, Sector 2, Noida-201301 UP, India 


\section{Introduction}

Globally, ${ }^{1}$ before diabetic neuropathy, leprosy was the commonest peripheral nerve disorder and people of countries like India and Brazil were deformed and disabled due to it. Due to significant peripheral nerve involvement, leprosy became a stigmatizing public health issue of great dimension. In leprosy, cutaneous manifestation aids in early identification and neural deficits causes disability and stigma. Early detection and treatment prevents disability and deformity. ${ }^{2}$ Disability due to leprosy is common with 3 million people suffering worldwide. ${ }^{3}$ Projections of global leprosy burden estimated 5 million new cases to occur between 2000 AD and next 20 years, with 1 million fresh grade-2 (severe) disabilities.

Though leprosy affects both central and peripheral nervous system, peripheral nerves are commonly involved. Neuropathy affects motor, sensory, and autonomic divisions of peripheral nervous system. Clinical examination was the corner stone of suspecting and diagnosing leprosy with confirmation by skin and ear lobe smear examination. Intense vigilance and the National Leprosy Eradication Program (NLEP) measures lead to elimination of leprosy by 2005 in India, but eradication is still a dream. In some states of India, current prevalence exceeded elimination point with rising child hood cases. ${ }^{4,5}$ In India, between time periods, 2006 to 2015, prevalence was 5.9 and 11.2\% in Kerala and Karnataka, respectively, among children. ${ }^{6}$ Children have increased susceptibility to leprosy due to their lack of immunity and exposure to patients within family. The proportion of children among new cases indicates continued disease propagation., ${ }^{7,8}$ Electrophysiology features of leprous neuropathy were initially outlined in the 1960 s. $^{8}$ By the 1970 s, details of electrophysiological abnormalities became more clear. Though many characteristic features were described till date, even today, it is not utilized for diagnosis and prognosis. ${ }^{9}$ Many reasons prevented routine use of electrophysiology in diagnosing and prognosticating leprous neuropathy. Factors, like stable temperature and electrical supply required for the machine, can be overcome by temperature controlled cabin vans with unlimited power supply aided by solar energy. Other reasons like very costly equipment and technical expertise had changed in recent times.

\section{Objective}

This study was aimed to determine the clinical and electrophysiological features of leprous neuropathy, so that it can be diagnosed early and accurately with the available aids.

\section{Materials and Methods}

Clinical and electrophysiological abnormalities in 36 histopathology proven leprosy patients between January 2015 and January 2017 in the age group of 5 to 69 years (27 males and 9 females) were studied. ${ }^{10}$

\section{Study Design}

This is an observational study.

\section{Setting}

The study was conducted at a multispecialty teaching hospital.

\section{Results}

Clinical abnormality with respect to nerve involvement is shown in - Table 1 .

Fifteen patients presented with only skin lesions, 14 both nerve and skin involvement, and 7 nerve involvement alone. Duration of disease varied from 6 months to 2 years. All patients had neural involvement, either clinically or by electrophysiology.

Total of 132 nerves were clinically affected out of 1,008 examined (almost all peripheral nerves including cutaneous and digital nerves could be examined and palpated). Overall, 215 out of 504 (theoretically 576 nerves are possible but only 504 were tested) nerves tested were abnormal by electrophysiology. This difference between clinical and electrophysiology detection of nerve involvement is statistically significant, (Chi-square $=164.4054 ; p=0.0000$ ) in favor of electrophysiology.

Most affected nerve was ulnar, both clinically and electrophysiologically. Clinically out of 72 ulnar nerves examined, 27 were affected. When electrophysiology was done, 46 showed sensory and 38 showed motor abnormalities. Comparing clinical manifestation and electrophysiological (sensory) abnormality, latter was found to be statistically significant in picking up neuropathy in favor

Table 1 Details of nerves affected clinically

\begin{tabular}{|l|l|l|}
\hline Sl. no & Nerve affected & $\begin{array}{l}\text { Numbers } \\
\text { involved }\end{array}$ \\
\hline 1. & Ulnar & 27 \\
\hline 2 & Radial cutaneous & 22 \\
\hline 3 & Common peroneal & 18 \\
\hline 4 & Dorsal cutaneous branch ulnar & 18 \\
\hline 5 & Superficial peroneal & 15 \\
\hline 6 & Sural & 9 \\
\hline 7 & Posterior tibial & 9 \\
\hline 8 & Radial & 6 \\
\hline 9 & Greater auricular & 4 \\
\hline 10 & Median & 2 \\
\hline 11 & Supraorbital & 2 \\
\hline 12 & Infraorbital & 2 \\
\hline 13 & Supratrochlear & 1 \\
\hline 14 & Supraclavicular & 1 \\
\hline
\end{tabular}


of electrophysiology (Chi-square $=9.0017 ; p=0.0026$ ). Seventy-two median nerves were palpated but only two were thickened. Electrophysiology showed 33 sensory abnormalities (Chi-square $=33.92 ; p=0.000$ ) and 10 motor abnormalities (Chi-square $=4.4545 ; p=0.034$ ) in median nerve. These differences were statistically significant (-Table 2).

Clinically, 29 patients had mononeuritis multiplex (including sensory and motor), 5 mononeuritis, and 2 were without nerve involvement. With electrophysiology, 32 patients had mononeuritis multiplex, 2 mononeuritis, and 2 normal conduction parameters.

Addressing the fraction of demyelination and axonopathy in the patients, 146 out of 215 (68\%) had demyelination, while 77 (36\%) had axonopathy. There were overlaps in the electrophysiology findings as shown in - Table 3.

\section{Discussion}

Three clinical and electrophysiological features noticed in the series of 36 patients are as follows:

1. Subclinical neuropathy (electroclinical dissociation).

2. Mononeuritis multiplex or mononeuritis (clinically and electrophysiologically).

3. Mosaic pattern of combined demyelinating and axonal changes (in electrophysiology).

\section{Subclinical Neuropathy (Electroclinical Dissociation)}

Subclinical neuropathy was evidenced by more nerve abnormalities detected by electrophysiology than clinical examination and was statistically significant (exception in two patients). ${ }^{8,11}$ In leprosy patients, even when there was no evidence of clinical neural involvement, conduction slowing of sensory and motor nerves were present. This subclinical neuropathy precedes symptoms and signs of leprosy. ${ }^{12}$ This is important because before other features of leprous neuropathy, slowing occurs in sensory nerve conduction (as early as 12 weeks before other tests becomes abnormal). ${ }^{12}$ At this stage of subclinical neuropathy, if treated suitably, ongoing nerve damage and disability can be prevented. Always clinical examination should be followed by electrophysiology if neuropathy is suspected. ${ }^{13,14}$ Electrophysiology is indicated for workup of all cases of peripheral neuropathy after a very basic hematological and biochemical workup. Hence, it is indicated in all leprosy suspects and patients, because in all leprosy cases, there is subclinical neuropathy. ${ }^{14,15}$ In other words, electrophysiology is extended clinical examination which should be used wherever indicated like leprosy. From the series of 36 patients, authors came to conclusion that electrophysiology scored better than clinical examination but there should be a combined approach for detecting all cases. ${ }^{16}$ In INFIR cohort study, van Brakel et al proposed that nerve conduction study (NCS)/electrophysiology should be considered as gold standard in detecting leprous neuropathy.

Electroclinical dissociation, ${ }^{16,17}$ indicative of subclinical neuropathy is evident in many studies and in present series. It was evident in both ulnar and median nerves, but pronounced in median nerves, which was reported in early studies and present in the current series. Whereas clinically affected nerves were 132 out of 1,008 , (13.1\%), by electrophysiology, they were 215 out of 504 (43\%), suggesting dissociation between clinical and electrophysiologic findings..$^{18}$ Ramakrishnan and Srinivasan observed electrophysiologically evident nerve dysfunction to occur earlier than clinical manifestation. ${ }^{18}$ In that study, they found that clinically unaffected nerves had reduced amplitudes than conduction velocities. ${ }^{19}$ Thus electroclinical dissociation was noticed by the $1990 \mathrm{~s}^{19}$ The dissociation between clinical examinations of various types and testing was analyzed with NCS as gold standard..$^{19}$ Dissociation with reduced sensitivity to nerve palpation was present in median, ulnar, great auricular, and common peroneal nerves. In the current study, electroclinical dissociation was present in all nerves tested except peroneal sensory.

In considering those with electroclinical dissociation, 34 patients each had abnormal electrophysiology and clinical examination. The number of patients tested normal with regard to either clinical or electrophysiology were

Table 2 Comparing clinical versus electrophysiology in leprous neuropathy

\begin{tabular}{|l|l|l|l|l|l|l|l|}
\hline $\begin{array}{l}\text { Nerve type } \\
\text { tested }\end{array}$ & $\begin{array}{l}\text { Nerves } \\
\text { examined } \\
\text { clinically }\end{array}$ & $\begin{array}{l}\text { Clinically } \\
\text { abnormal } \\
\text { (thick) }\end{array}$ & $\begin{array}{l}\text { Total } \\
\text { nerves } \\
\text { tested-EP }\end{array}$ & $\begin{array}{l}\text { EP abnormal } \\
\text { nerves }\end{array}$ & $\begin{array}{l}\text { Clinical/EP } \\
\text { comparison } \\
\text { (Chi-squire) }\end{array}$ & $p$-Value & $\begin{array}{l}\text { Statistical } \\
\text { significance }\end{array}$ \\
\hline Total nerves & 1,008 & 132 & 504 & 215 & 164.40 & 0.0000 & Yes \\
\hline Ulnar sensory & 72 & 27 & 72 & 46 & 9.0019 & 0.0027 & Yes \\
\hline Ulnar motor & 72 & 27 & 72 & 38 & 2.8043 & 0.0940 & No \\
\hline Median sensory & 72 & 2 & 72 & 33 & 33.920 & 0.0000 & Yes \\
\hline Median motor & 72 & 2 & 72 & 10 & 4.4545 & 0.0348 & Yes \\
\hline Sural & 72 & 9 & 72 & 14 & 0.8279 & 0.3628 & No \\
\hline Peroneal sensory & 72 & 15 & 72 & 16 & 0.0411 & 0.8393 & No \\
\hline Peroneal motor & 72 & 18 & 72 & 26 & 1.603 & 0.2600 & No \\
\hline Posttibial & 72 & 9 & 72 & 32 & 16.502 & 0.0000 & Yes \\
\hline
\end{tabular}

Abbreviation: EP, electrophysiological. 
Table 3 Electrophysiological changes in nerves

\begin{tabular}{|l|l|l|l|l|}
\hline $\begin{array}{l}\text { Sl. } \\
\text { no }\end{array}$ & Nerve tested & $\begin{array}{l}\text { Nerves with increased } \\
\text { latency (demyelination) } \\
n(\%)\end{array}$ & $\begin{array}{l}\text { Nerves with reduced } \\
\text { amplitude (axonopathy) } \\
\boldsymbol{n}(\%)\end{array}$ & $\begin{array}{l}\text { Nerves with decreased velocity } \\
\text { (demyelination) } \\
\boldsymbol{n}(\%)\end{array}$ \\
\hline 1 & Ulnar sensory & $24 / 46(52)$ & $12 / 46(26)$ & $33 / 46(72)$ \\
\hline 2 & Ulnar motor & $24 / 38(63)$ & $5 / 38(13)$ & $29 / 38(76)$ \\
\hline 3 & Median sensory & $24 / 33(73)$ & $6 / 33(18)$ & $29 / 33(88)$ \\
\hline 4 & Median motor & $8 / 10(80)$ & $0 / 10(0)$ & $10 / 10(100)$ \\
\hline 5 & Sural & $10 / 14(71)$ & $9 / 14(64)$ & $5 / 14(36)$ \\
\hline 6 & Peroneal sensory & $10 / 16(63)$ & $13 / 16(81)$ & $9 / 16(56)$ \\
\hline 7 & Peroneal motor & $9 / 26(35)$ & $13 / 26(50)$ & $11 / 26(42)$ \\
\hline 8 & Posterior tibial & $9 / 32(28)$ & $9 / 32(28)$ & $17 / 32(53)$ \\
\hline & Total nerves & $118 / 215(54.8)$ & $67 / 215(35.8)$ & $143 / 215(67.9)$ \\
\hline
\end{tabular}

equal (two). But the number of nerves identified as abnormal was more with electrophysiology. Chance for missing diagnosis of leprosy was there in this series if clinical examination alone was used. Clinical examination did not reveal pathology of several nerves and two patients. With electrophysiology alone, there was a chance for missing diagnosis in two patients. This will not occur in real-life situation. Electrophysiology will be used only as an additional aid after clinical examination. ${ }^{20}$ When both are combined, all patients and neural abnormalities could be detected as evidenced from this series. Thus as a single test, electrophysiology is better, but combination of clinical examination and electrophysiology is the best approach. ${ }^{21}$ When sympathetic skin response (SSR) was combined with routine electrophysiology, features of nerve dysfunction identified was $81.8 \%$, as it will identify small fiber involvement. In the current study, SSR was not done, as it required more expertise and time consumption. Our aim was to know the electrophysiological abnormalities with routine nerve conduction tests by a regular technician with minimum time consumption, so that it can be used in the rural society (field setting).

\section{Mosaic Pattern of Neuropathy ${ }^{22}$}

Electrophysiological abnormalities were neither purely demyelinating nor axonal. It was mosaic pattern of $68 \%$ demyelinating and 36\% axonal with overlap. ${ }^{13}$ Electrophysiological abnormalities reported were reduced amplitude of motor and sensory potential (axonopathy) or prolonged latencies and slowing of conduction velocity (demyelination). ${ }^{7,8}$ Different authors have found varying pattern of neurophysiological abnormalities in leprous neuropathy. Electrophysiological changes recognized in the 1970s were predominantly conduction slowing of motor nerves in early disease and reduced amplitudes in clinically advanced cases..$^{9,12,23}$ It is now known that sensory nerves are identified to be involved in the early disease phase. ${ }^{18}$ Certain investigators were of the opinion that sensory nerve action potential (SNAP) and compound nerve action potential (CNAP) amplitudes were more suggestive of early neuropathy than slowing of velocity. ${ }^{12}$ ILEP nerve function impairment study was a prospective study which looked into what factors in electrophysiology predicted nerve function impairment to occur in future. It was found that both motor and sensory nerve conduction slowing predicted future nerve function impairment, but it was more predictable with sensory. ${ }^{23}$ In another study, sensory conduction velocity was found to be slow. ${ }^{24}$ Axonopathy of motor nerves are also described. Electromyography showed denervation of small muscles of hand which indicated axonopathy of ulnar nerves. ${ }^{25}$ But before symptom onset of neuropathy, there is conduction slowing in sensory and motor nerves. Thus, short demyelinating and axonal changes (mosaic pattern $)^{22}$ can be seen, in leprous neuropathy, as it is seen in the current series. Here, in most nerves, the abnormality was predominantly demyelination, while in peroneal motor and sensory and sural nerves, it was predominantly axonopathy. ${ }^{26,27}$ In another study, 98\% had electrophysiological abnormalities. They found reduction of SNAP and compound muscle action potential (CMAP) to be the earliest and commonest change. ${ }^{22}$ Thus, a mosaic pattern peripheral neuropathy points to leprous neuritis by electrophysiology.

\section{Mononeuritis Pattern}

Motor weakness in nerve distribution was present in 17 patients. Clinical peripheral nerve involvement is shown in - Tables 1 and $\mathbf{2}$. Thus both clinically and electrophysiologically, pattern was mononeuritis/mononeuritis multiplex..$^{28}$ Mononeuritis multiplex occurs most commonly due to leprosy and systemic vasculitis. ${ }^{29}$ Leprosy is the disease with skin lesions and mononeuritis of small sensory nerves, later involving motor trunks. Thus it produces mononeuritis or mononeuritis multiplex. When mononeuritis is caused by vasculitis, it is axonal; whereas in leprosy, histopathology and electrophysiology characterize more of motor demyelinating neuropathy. There is also conduction block.

Thus, when the electrophysiology shows subclinical neuropathy with electroclinical dissociation in a mononeuritis or mononeuritis multiplex type of nerve involvement and mosaic pattern of both demyelination and axonal changes, in an endemic area, with or without contact history, one should strongly consider and rule out leprosy and leprous neuropathy. Even in a person with peripheral neuropathy without 
contact history, if electrophysiology suggests all three features, that is, subclinical neuropathy (electroclinical dissociation), mosaic pattern of demyelination, and axonopathy in mononeuritis or mononeuritis multiplex distribution, one should strongly consider leprous neuritis. This approach of incorporating electrophysiology for diagnosing neuropathy in leprosy at a very early stage will help in reducing the disability and deformity.

\section{Conclusion}

Use of electrophysiology in leprosy will enable early detection of neuropathy, prompt treatment, and prevention of disability and stigma. Nerve conduction study (electrophysiology) is of great help in identification of neuropathy in new cases, (enabling zero disability) follow-up of known cases will definitely contribute toward a near-total freedom from disability among leprosy patients.

\section{Conflict of Interest}

None declared.

\section{References}

1 Hammi C, Yeung B, Neuropathy. In: StatPearls. Treasure Island, FL: StatPearls Publishing; 2020

2 Pannikar V. Enhanced global strategy for further reducing the disease burden due to leprosy: 2011-2015 Lepr Rev. 2009;80(4):353-354

3 Richardus JH, Habbema JD. The impact of leprosy control on the transmission of $M$. leprae: is elimination being attained? Lepr Rev 2007;78(4):330-337

4 Devi K, Renu V, Asokan N, Ambooken B. Childhood leprosy in the light of global leprosy strategy 2016-2020. Indian J Lepr 2019;91(1):1-6

5 Babu A, Bhat MR, Jayaraman J. Childhood leprosy in the postelimination era: A vision achieved or a concern growing at large. Indian J Paediatr Dermatol 2018;19:26-30

6 World Health Organization. Leprosy: world focused on ending transmission among children. Accessed October 4, 2020 atat https://www.who.int/neglected_diseases/ news/Leprosy_ending_transmission_among_children/en/.

7 Hackett ER, Shipley DE, Livengood R. Motor nerve conduction velocity studies of the ulnar nerve in patients with leprosy. Int J Lepr Other Mycobact Dis 1968;36(3):282-287

8 Verghese $M$, Ittimani KV, Satyanarayan KR, Mathai $R$, Bhakthaviziam C. A study of the conduction velocity of the motor fibers of ulnar and median nerves in leprosy. Int J Lepr Other Mycobact Dis 1970;38(3):271-277

9 Wagenaar I, Post E, Brandsma W, et al. Early detection of neuropathy in leprosy: a comparison of five tests for field settings. Infect Dis Poverty 2017;6(1):115

10 Vasanthy B, Nair VCP, Haris AA, George J. Nerve conduction study for early detection of leprosy. Int J Med Health Res 2018;4(12):4-8
11 Husain S, Malaviya GN. Early nerve damage in leprosy: an electrophysiological study of ulnar and median nerves in patients with and without clinical neural deficits. Neurol India 2007;55(1):22-26

12 van Brakel WH, Nicholls PG, Wilder-Smith EP, Das L, Barkataki P, Lockwood DN; INFIR Study Group. Early diagnosis of neuropathy in leprosy-comparing diagnostic tests in a large prospective study (the INFIR cohort study) PLoS Negl Trop Dis 2008;2(4):e212

13 Siao P, Kaku M. A clinician's approach to peripheral neuropathy. Semin Neurol 2019;39(5):519-530

14 HughesRA.Peripheralneuropathy.BMJ2002;324(7335):466-469

15 Vodusek DB, Amarenco G, S Podnar. Clinical neurophysiological tests. In: Abrams P, Cardozo L, Khoury S, Wein A, eds. Incontinence. 4th ed. Plymouth, United Kingdom: Health Publication Ltd; 2009:523-540

16 Van Brakel WH, Nicholls PG, Das L, et al. The INFIR Cohort Study: assessment of sensory and motor neuropathy in leprosy at baseline. Lepr Rev 2005;76(4):277-295

17 Brown TR, Kovindha A, Wathanadilokkol U, Piefer A, Smith T, Kraft GH. Leprosy neuropathy: correlation of clinical and electrophysiological tests. Indian J Lepr 1996;68(1):1-14

18 Ramakrishnan AG, Srinivasan TM. Electrophysiological correlates of hanseniasis. Int $\mathrm{J}$ Lepr Other Mycobact Dis 1995;63(3):395-408

19 Kumar N, Malhotra HS, Garg RK, et al. Comprehensive electrophysiology in leprous neuropathy - Is there a clinico-electrophysiological dissociation? Clin Neurophysiol 2016;127(8):2747-2755

20 Samant G, Shetty VP, Uplekar MW, Antia NH. Clinical and electrophysiological evaluation of nerve function impairment following cessation of multidrug therapy in leprosy. Lepr Rev 1999;70(1):10-20

21 Cabalar M, Yayla V, Ulutas S, Senadim S, Oktar AC. The clinical \& neurophysiological study of leprosy. Pak J Med Sci 2014;30(3):501-506

22 Jardim M, Vital R, Balassiano S, Hacker M, Illarramendi X, Sarno E. Pattern of nerve conduction study in leprosy neuropathy. Neurology 2014;82(10):319-321

23 Sebille A. Respective importance of different nerve conduction velocities in leprosy. J Neurol Sci 1978;38(1):89-95

24 Ramadan W, Mourad B, Fadel W, Ghoraba E. Clinical, electrophysiological, and immunopathological study of peripheral nerves in Hansen's disease. Lepr Rev 2001;72(1):35-49

25 Kar S, Krishnan A, Singh N, Singh R, Pawar S. Nerve damage in leprosy: An electrophysiological evaluation of ulnar and median nerves in patients with clinical neural deficits: a pilot study. Indian Dermatol Online J 2013;4(2):97-101

26 Lastória JC, Abreu MA. Leprosy: a review of laboratory and therapeutic aspects-part 2. An Bras Dermatol 2014;89(3):389-401

27 DeFaria CR, Silva IM. Electromyographic diagnosis of leprosy. Arq Neuropsiquiatr 1990;48(4):403-413

28 Misra UK, Kalita J, Nair PP. Diagnostic approach to peripheral neuropathy. Ann Indian Acad Neurol 2008;11(2):89-97

29 Donofrio P. AAEM mlnlmonograph \#34.polyneuropathy: classification by nerve conduction studies and electromyography. Muscle Nerve 1990;13(10):889-903 